\title{
CARMEN BLACKER
}

SCHOLAR OF JAPANESE RELIGION, MYTH AND FOLKELORE 



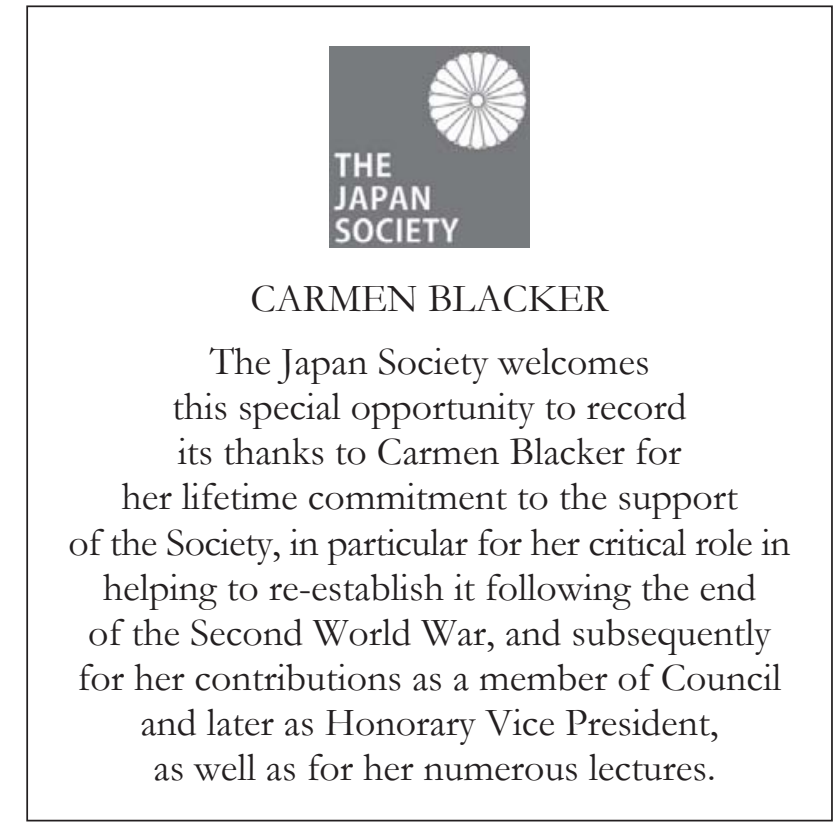




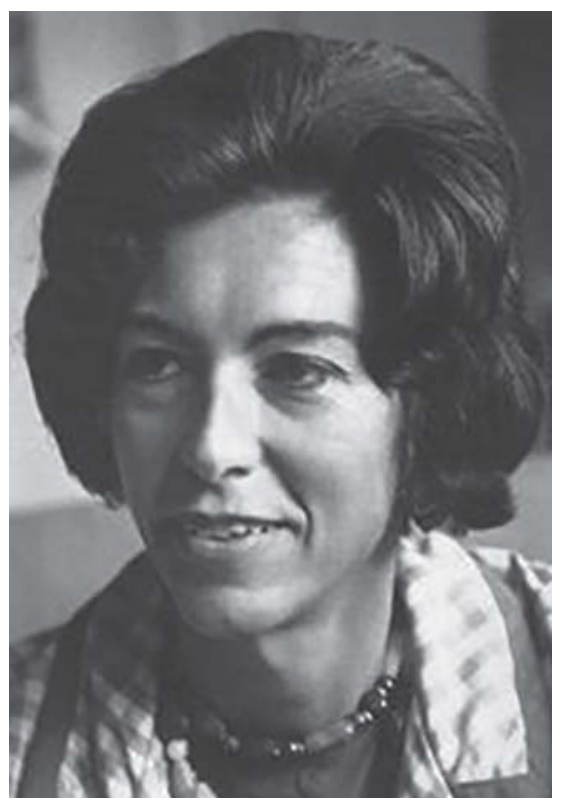

Carmen Blacker, c.1970s 


\title{
Carmen Blacker
}

\section{SCHOLAR OF JAPANESE RELIGION, MYTH AND FOLKELORE}

WRITINGS AND REFLECTIONS

\author{
$\mathscr{H}$ \\ Edited by \\ Hugh Cortazzi \\ With \\ James McMullen \& Mary-Grace Browning
}

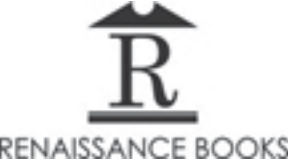


CARMEN BLACKER

SCHOLAR OF JAPANESE RELIGION, MYTH AND FOLKELORE

Writings and Reflections

First published 2017 by

RENAISSANCE BOOKS

P O Box 219

Folkestone

Kent CT20 2WP

Renaissance Books is an imprint of Global Books Ltd

ISBN 978-1-898823-56-8 Hardback

978-1-898823-57-5 e-Book

(C) Global Books Ltd 2017

All rights reserved. No part of this publication may be reproduced, translated, stored in a retrieval system, or transmitted in any form or by any means, electronic, mechanical, photocopying, recording, or otherwise, without prior written permission from the publishers.

\section{SPECIAL THANKS}

The Executive Director and Members of the Board of the Sainsbury Institute for the Study of Japanese Arts and Cultures, together with the Publishers, wish to express their thanks to the Great-Britain Sasakawa Foundation for their support in the making of this book.

\section{British Library Cataloguing in Publication Data}

A catalogue record for this book is available from the British Library

Set in Garamond 11.5 on 12.5 pt by Dataworks

Printed and bound in England by CPI Antony Rowe Ltd., Chippenham, Wilts 